Journal of Environmental Sciences (JES)

Institute of Environmental Studies and Research, Ain Shams University

El-Sherbiny, Hanan et al.

\title{
THE USE OF ULTRASOUND IN THE PREDICTION OF FETAL COMPLICATIONS AMONG DIABETIC PATIENTS IN LATE PREGNANCY
}

\author{
Hanan A. El-Sherbiny ${ }^{(1)}$; Hala I. Awad Allah ${ }^{(2)}$ \\ Alaa El-Din A. El-Guindy ${ }^{(3)}$
}

1) Boulak El-Dakrour General Hospital 2) Institute of Environmental Studies and Research, Ain Shams University 3) Faculty of Medicine, Ain Shams University

\begin{abstract}
Background: Diabetes mellitus, one of the most common medical complications, has become a major challenging threat in a pregnant woman. It is associated with various maternal and fetal complications which include polyhydramnios, macrosomia, operative interference, shoulder dystocia, birth injuries and perinatal mortality. Effective treatment of pre-existing as well as gestational diabetes mellitus and early prediction of fatal complications will improve outcome and reduce perinatal mortality.

Aim of the study: Evaluate the effect of diabetes mellitus on fetal outcome. Assess role of ultrasound in prediction of fetal complications in late diabetic pregnancy using sonographic fetal parameters. Compare between diabetic and non-diabetic regarding ultrasonographic fetal measurements and occurrence of maternal and fetal complications.

Patients and Methods: A prospective study including 82 women with diabetic pregnancy (diabetic group) and 156 pregnant women with normal GTT were included in this study and considered as control group. It was conducted in Boulak El-Dakrour General Hospital over a period of 2 years. Women in both groups were subjected to ultrasonographic examination at 2728 weeks of gestation and at 36-37 weeks. At each examination fetal anthroprometric parameters, umbilical cord thickness and hemodynamic parameters of umbilical artery were measured.
\end{abstract}


Journal of Environmental Sciences (JES)

Institute of Environmental Studies and Research, Ain Shams University

El-Sherbiny, Hanan et al.

Results: of the present study revealed that: There was significant difference between diabetic and control groups regarding sonographic predictors of fetal macrosomia in term of abdominal circumference, estimated fetal body weight and Wharton's jelly area. Fetuses of mothers in the diabetic group showed statistically significant increase of fetal macrosomia, low birth weight and intrauterine fetal demise in comparison to the control group; the diabetic group showed statistically significant increase of cesarean delivery in comparison to the control group. Conclusion: The results of the present study suggest the possibility of using sonographically determined fetal abdominal circumference, Wharton's jelly area, estimated fetal body weight measurements to distinguish women at high risk for abnormal fetal growth and disproportion potentially resulting in early detection and reducing fetal morbidity. In addition, these parameters can be considered as an effective, noninvasive and cost-effective method that can prove useful for evaluating the fetal consequences of maternal hyperglycemia.

Keywords: Ultrasound, prediction of fetal complications, diabetic patients, late pregnancy.

\section{INTRODUCTION}

Diabetes mellitus (DM) is one of the most common non-communicable diseases (NCD), with serious consequences. NCD kill over 36 million people worldwide each year, of this 36 million, over 1.3 million are attributable to DM (Daniela, 2017). Diabetic pregnancies can be divided into two categories, those with pre-existing diabetes mellitus in which the diagnosis is made in the pre-pregnancy state, and those with gestational diabetes mellitus (GDM). Preexisting diabetes consists of type 1 (insulin-dependent) diabetes with an incidence of around $0.5 \%$, and type 2 (non-insulin-dependent) diabetes with an incidence of $2-3 \%$. The incidence of gestational diabetes mellitus differs in different populations and ethnic groups (Williams, 2011). The pathological 
Journal of Environmental Sciences (JES)

Institute of Environmental Studies and Research, Ain Shams University

El-Sherbiny, Hanan et al.

conditions encountered in fetuses of diabetic pregnancies differ in those with pre-existing diabetes mellitus and those with gestational diabetes. Pre-existing diabetics with persistent hyperglycemia in the perinatal period are at higher risks of congenital malformations. In addition, those women with longstanding disease run a higher risk of having diabetic vasculopathy which may affect normal growth and development of the fetus (Reece and Homko, 2007). GDM has become the most common complication and most challenging threat to pregnant woman. GDM cases have risk of developing maternal complications like hypertension, pre-eclampsia, polyhydramnios and post-partum hemorrhage, and fetal complications like intra-uterine growth restriction (IUGR), macrosomia, stillbirth and respiratory distress syndrome GDM places the offspring at risk of insulin resistance and type 2 diabetes mellitus (DM), obesity and cardiovascular disease (Muhil et al., 2018). The International Diabetes Federation (IDF) listed Egypt among the world top 10 countries in the number of patients with diabetes. Obesity, especially visceral adiposity, and physical inactivity are major risk factors for diabetes in Egypt. It is alarming that diabetes prevalence in Egypt has increased rapidly within a relatively short period from approximately 4.4 million in 2007 to 7.5 million in 2013 (Hegazi et al., 2015). Effective treatment of pre-existing as well as gestational diabetes mellitus and early prediction of fetal complications will improve outcome and reduce perinatal mortality (Williams, 2011). Recent developments in technology and science have caused a dramatic evolution in obstetric practice as in all areas of life. 
Journal of Environmental Sciences (JES)

Institute of Environmental Studies and Research, Ain Shams University

El-Sherbiny, Hanan et al.

Modern sonographic technology is the one actual example (Binber et al., 2012).

The foundation for the use of ultrasound for the pregnant diabetic woman is early identification of congenital malformations and recognition of deviant fetal growth. In the case of fetal malformations, ultrasound technology will enhance well-timed options for the mother and, if needed, safer pregnancy termination. In addition, ultrasound provides an instrument for evaluation of deviant fetal growth and fetal weight estimation for timely delivery (Langer et al., 2005). In this study, we investigated the role of ultrasound in prediction of fetal complications among diabetic patients in late pregnancy through measurement of: Fetal biometry and estimated fetal body weight. Umbilical cord thickness and determination of Doppler velocity wave forms of umbilical artery.

\section{PATIENTS AND METHODS}

This prospective study extended from November 2016 to November 2018 which included 82 pregnant patients who had abnormal GTT (gestational or pregestational diabetes) and considered as cases or diabetic group. Nondiabetic 156 pregnant women who had normal GTT were included in this study and considered as control group. Both study and control group were recruited from the attendants of the outpatient Obstetric Clinic of Boulak ElDakrour General Hospital. An informed consent was taken from all participants or their relatives after explaining the sequence of procedures that 
they would be subjected to them. All of participants in the study were informed that they were allowed to stop participation in the procedures whenever they want. The study protocol was approved by the Ethical Committee of our Institution.

Inclusion Criteria: - Pregnant women with mono-fetal pregnancy. Gestational age $\geq 27$ weeks. - For study group, a diagnosis of pregestational or gestational diabetes. - Intact membranes. - Normal umbilical cord morphology ( 2 arteries and 1 vein).

Exclusion Criteria: - Multi-fetal pregnancy. - Presence of fetal congenital anomalies. - Maternal chronic diseases (hypertension renal, cardiac and pulmonary diseases). All patients were subjected to the following: - Thorough history taking with special emphasis on the presence of risk factors for gestational diabetes including family history of diabetes and obesity, gravidity, parity, history of gestational diabetes or previous macrosomic or malformed fetus, history of previous hypertension or any medical diseases (e.g. renal, cardiovascular or pulmonary diseases) and any history of medication consumption or smoking. - Thorough general and abdominal examination was done. - For each woman we registered age, height and body mass index (BMI). - Antenatal care investigations (CBC, blood glucose and HbA1c and complete urine analysis) were done. - Pregestational diabetic cases in the study were 27 and defined as diabetes starting before conception with initiation of glucose lowering medications either insulin or oral hypoglycemic drugs. Most of patients on oral medications were moved to 
Journal of Environmental Sciences (JES)

Institute of Environmental Studies and Research, Ain Shams University

El-Sherbiny, Hanan et al.

insulin treatment under supervision of endocrinologist. - Gestational diabetic cases were 55 and were diagnosed after screening with 50 gm glucose challenge test (GCT) if 1 hour plasma glucose was >140 mg/dl then next confirmatory step was done by $100 \mathrm{gm}$ three oral glucose tolerance test (GTT) (normal values: fasting glucose $<95 \mathrm{mg} / \mathrm{dl}$, 1 hour $<180 \mathrm{mg} / \mathrm{dl}, 2$ hours $<155 \mathrm{mg} / \mathrm{dl}$, and 3 hours $<140 \mathrm{mg} / \mathrm{dl}$, GDM was diagnosed when two values were elevated. Glycated $\mathrm{Hb}$ was done for all women of the study at 27-28 weeks gestations and was considered abnormal if $>6.5$ and repeated at 36-37 weeks for diabetic patients. The criteria for diagnosis of gestational induced hypertension were systolic blood pressure $\geq 140 \mathrm{mmHg}$ and/or diastolic blood pressure $\geq 90 \mathrm{mmHg}$. Calculation of gestational age was based on the last reliable menstrual period and confirmed by ultrasound examination which was performed with (Mindray D30) equipped with 3.5-mHZ transabdominal probe. All patients in both groups were subjected to ultrasonographic examination at 27-28 weeks of gestation and at 36-37 gestation weeks. Ultrasonographic examination included fetal anthropometric parameters, biparietal diameter (BPD), abdominal circumference (AC), femur length (FL) and estimated fetal weight (EFW), which was calculated automatically according to Hadlock's formula. Umbilical artery (UA) Doppler indices [pulsatility index (PI), resistance index (RI) and systolic/diastolic ratio (S/D)] were measured. Additionally, the sonographic cross-sectional area of the umbilical cord and umbilical vessels was measured in a free loop of the umbilical cord by software provided by ultrasonography machine. The cross- 
sectional area of Wharton's jelly was calculated by subtracting the area of the vessels from the total area of the cord which was an estimate of umbilical cord thickness. Women were followed till the time of delivery to observe maternal and neonatal outcomes. Type of delivery was registered, and birth weight of the baby was measured. Macrosomia was defined as birth weight $\geq 4000 \mathrm{~kg}$ and low birth weight when $<2500 \mathrm{~kg}$. The resultant data was tabulated and statistical analysis was done. Data analysis: Data was computed and analyzed by using SPSS software. $\mathrm{P}$ value $<0.05$ was considered significant.

\section{RESULTS}

Table (1): Comparison between diabetic and control groups regarding quantitative variables of clinical characteristics

\begin{tabular}{|c|c|c|c|c|}
\hline \multirow[b]{2}{*}{ Variable } & \multicolumn{2}{|c|}{ Group } & \multirow[b]{2}{*}{ t-Test } & \multirow[b]{2}{*}{$\mathbf{P}$} \\
\hline & $\begin{array}{c}\text { Case (Diabetic) } \\
\text { Mean } \pm \text { SD } \\
(\text { No. 82) }\end{array}$ & $\begin{array}{l}\text { Control (Non- } \\
\text { diabetic) } \\
\text { Mean } \pm \text { SD } \\
(\text { No. 156) }\end{array}$ & & \\
\hline Age (years) & $32.09 \pm 3.5$ & $29.69 \pm 5.9$ & 3.325 & $0.001(\mathrm{~S})$ \\
\hline $\begin{array}{c}\text { Body mass index } \\
\left(\mathrm{Kg} / \mathrm{m}^{2}\right)\end{array}$ & $29.66 \pm 7.3$ & $31.61 \pm 21.06$ & 0.710 & $0.41(\mathrm{NS})$ \\
\hline $\begin{array}{l}\text { No. of living } \\
\text { children }\end{array}$ & $2.89 \pm 1.46$ & $2.36 \pm 1.52$ & 2.583 & $0.010(\mathrm{~S})$ \\
\hline $\begin{array}{l}\text { No. of abortions } \\
\text { and still birth }\end{array}$ & $1.62 \pm 1.22$ & $0.93 \pm 0.97$ & 4.746 & $0.001(\mathrm{~S})$ \\
\hline $\begin{array}{l}\text { Gestational age at } \\
\text { delivery (weeks) }\end{array}$ & $36.89 \pm 1.12$ & $38.30 \pm 1.38$ & -7.805 & $0.001(\mathrm{~S})$ \\
\hline
\end{tabular}

NS: Statistically non-significant difference 
This table demonstrates that: There was significant difference between study and control groups regarding age, No. of living children, abortions and stillbirths and gestational age at delivery.

Table (2): Comparison between diabetic and control groups regarding sonographic predictors of fetal macrosomia (at 36-37 weeks)

\begin{tabular}{|c|c|c|c|c|}
\hline \multirow{2}{*}{$\begin{array}{c}\text { Sonographic } \\
\text { predictors of fetal } \\
\text { macrosomia }\end{array}$} & \multicolumn{2}{|c|}{ Group } & \multirow[b]{2}{*}{$\begin{array}{c}\text { t- } \\
\text { Test }\end{array}$} & \multirow[b]{2}{*}{$\mathbf{P}$} \\
\hline & $\begin{array}{c}\text { Case (Diabetic) } \\
\text { Mean } \pm \text { SD }\end{array}$ & $\begin{array}{c}\text { Control (Non- } \\
\text { diabetic) Mean } \pm \text { SD }\end{array}$ & & \\
\hline $\begin{array}{c}\text { Abdominal } \\
\text { circumference }(\mathrm{Cm})\end{array}$ & $37.41 \pm 2.96$ & $34.97 \pm 2.74$ & 6.08 & $\begin{array}{l}0.0001 \\
(\mathrm{~S})\end{array}$ \\
\hline $\begin{array}{l}\text { Umbilical cord } \\
\text { thickness (Whrton's } \\
\text { jelly area) }\left(\mathrm{Cm}^{2}\right)\end{array}$ & $2.43 \pm 0.27$ & $2.37 \pm 0.15$ & 2.14 & $0.03(\mathrm{~S})$ \\
\hline $\begin{array}{l}\text { Estimated fetal body } \\
\text { weight (gm) }\end{array}$ & $3969.28 \pm 539.05$ & $3167.05 \pm 389.142$ & 11.09 & $\begin{array}{l}0.0001 \\
(\mathrm{~S})\end{array}$ \\
\hline
\end{tabular}

This table demonstrates that: There was significant difference between diabetic and control groups regarding sonographic predictors of macrosomia. (Abdominal circumference, umbilical cord thickness and estimated fetal body weight) measured at 36-37 weeks of gestation 
Table (3): Comparison between case and control groups regarding fetal birth weight

\begin{tabular}{|c|c|c|c|c|}
\hline \multirow[b]{2}{*}{ Variables } & \multicolumn{2}{|c|}{ Group } & \multirow[b]{2}{*}{ t-test } & \multirow[b]{2}{*}{$\mathbf{P}$} \\
\hline & $\begin{array}{l}\text { Case (Diabetic) } \\
\text { Mean } \pm \text { SD (No. } \\
75)\end{array}$ & $\begin{array}{l}\text { Control (Non- } \\
\text { diabetic) Mean } \pm \\
\text { SD }(\text { No. 146) }\end{array}$ & & \\
\hline $\begin{array}{c}\text { Fetal birth weight } \\
(\mathrm{gm}) \text { mean } \pm \mathrm{SD}\end{array}$ & $4014.9 \pm 527.4$ & $3398.84 \pm 383.5$ & 9.913 & $0.001(\mathrm{~S})$ \\
\hline $\begin{array}{c}\text { No. of fetal } \\
\text { macrosomia* }\end{array}$ & $45(60 \%)$ & $15(10.3 \%)$ & \multirow{3}{*}{$\chi^{2} 67.7$} & \multirow{3}{*}{$0.001(\mathrm{~S})$} \\
\hline $\begin{array}{c}\text { No. of normal } \\
\text { birth weight }\end{array}$ & $27(36 \%)$ & $130(89 \%)$ & & \\
\hline $\begin{array}{l}\text { No. of low birth } \\
\text { weight* }\end{array}$ & $3(4 \%)$ & $1(0.7 \%)$ & & \\
\hline
\end{tabular}

* Macrosomia: Fetal birth weight $>4000$ gm

* Low birth weight: Fetal birth weight $<2500$ gm

This table shows that: There was significant difference between study and control groups regarding fetal birth weight either macrosomic, normal birth weight or low birth weight fetuses

Percentage of fetal macrosomia among diabetic group was $60 \%$ while in control group (non-diabetic) was $10.3 \%$, regarding low birth weight, its percentage among diabetic group was $4 \%$ and $0.7 \%$ among control group. While percentage of normal birth weight among diabetics was $36 \%$ and $89 \%$ among control group.

Seven cases from diabetic group and 10 cases from control group didn't attend the second ultrasonographic examination. At the end of the study 75 
patients in diabetic group and 146 patients in the control group were evaluated.

Table (4): Comparison between macrosomic (>4000 gm) and nonmacrosomic fetus as regard maternal glycated hemoglobin (HbA1c) among diabetic group

\begin{tabular}{|c|c|c|c|c|}
\hline $\begin{array}{c}\text { Maternal } \\
\text { HbA1c }\end{array}$ & $\begin{array}{c}\text { Macrosomic fetus } \\
\text { Mean } \pm \text { SD }\end{array}$ & $\begin{array}{c}\text { Non-macrosomic } \\
\text { fetus Mean } \pm \text { SD }\end{array}$ & t-Test & P \\
\hline \hline $\begin{array}{c}\text { HbA1c at } \\
(27-28 \text { weeks })\end{array}$ & $6.58 \pm 1.74$ & $5.13 \pm 0.71$ & 8.619 & $0.001(\mathrm{~S})$ \\
\hline $\begin{array}{c}\text { HbA1c at } \\
(36-37 \text { weeks })\end{array}$ & $8.03 \pm 1.4$ & $7.23 \pm 0.75$ & 2.698 & $0.009(\mathrm{~S})$ \\
\hline
\end{tabular}

There was significant difference between macrosomic and nonmacrosomic fetus regarding maternal glycated hemoglobin (HbA1c) measured at (27-28 weeks) and (36-37 weeks).

Table (5): Comparison between case and control groups regarding occurrence of maternal and fetal complications

\begin{tabular}{|c|c|c|}
\hline \multirow{2}{*}{ Variables } & \multicolumn{2}{|c|}{ Group } \\
\cline { 2 - 3 } & $\begin{array}{c}\text { Case (Diabetic) } \\
\text { No (\%) }\end{array}$ & $\begin{array}{c}\text { Control (Non-diabetic) } \\
\text { No (\%) }\end{array}$ \\
\hline \hline $\begin{array}{c}\text { Fetal macrosomia (body weight } \\
>4000 \text { gm) }\end{array}$ & $45(60 \%)$ & $15(10.3 \%)$ \\
\hline Low birth weight (<2500 gm) & $3(4.0 \%)$ & $1(0.7 \%)$ \\
\hline Preterm labour & $2(2.4 \%)$ & $4(2.6 \%)$ \\
\hline Intrauterine fetal death & $2(2.4 \%)$ & $1(0.6 \%)$ \\
\hline Occurrence of pre-eclampsia & $4(4.9 \%)$ & $5(3.2 \%)$ \\
\hline
\end{tabular}

This table demonstrates that: Percentage of fetal macrosomia was $60 \%$ among diabetic group while $10.3 \%$ among control group. 
Percentage of low birth weight babies of diabetic mothers was $4 \%$ while in non-diabetic was $0.7 \%$.

Percentage of preterm labour among diabetics was $2.4 \%$ while in nondiabetic was $2.6 \%$.

Percentage of intrauterine fetal death among diabetic women was $2-4 \%$ while in control was $0.6 \%$.

Regarding percentage of diabetic women with pre-eclampsia was $4.9 \%$ while in control group, percentage of pre-eclampsia was $3.2 \%$.

Table (6): Comparison between diabetic and control groups regarding fetal umbilical artery Doppler indices

\begin{tabular}{|c|c|c|c|c||}
\hline \multirow{2}{*}{$\begin{array}{c}\text { Indices of umbilical } \\
\text { artery Doppler }\end{array}$} & $\begin{array}{c}\text { Gase (Diabetic) } \\
\text { Mean } \pm \text { SD }\end{array}$ & $\begin{array}{c}\text { Control (Non- } \\
\text { diabetic) Mean } \pm \\
\text { SD }\end{array}$ & $\begin{array}{c}\text { t- } \\
\text { Test }\end{array}$ & P \\
\hline Resistance index & $0.629 \pm 0.07$ & $0.593 \pm 0.071$ & 3.511 & $0.001(\mathrm{~S})$ \\
\hline Systolic/diastolic & $2.63 \pm 0.27$ & $2.53 \pm 0.22$ & 3.004 & $0.003(\mathrm{~S})$ \\
\hline Pulsatility index & $0.655 \pm 0.089$ & $0.627 \pm 0.065$ & 2.695 & 0.08 (NS) \\
\hline
\end{tabular}

This table demonstrates that: There was significant difference between diabetic and control groups regarding fetal umbilical artery Doppler indices (Resistance index and systolic/diastolic) while was no significant difference regarding pulsatility index 
Journal of Environmental Sciences (JES)

Institute of Environmental Studies and Research, Ain Shams University

El-Sherbiny, Hanan et al.

Table (7): Comparison between diabetic and control groups regarding type of delivery

\begin{tabular}{|c|c|c|c|c|}
\hline \multirow[b]{2}{*}{ Type of delivery } & \multicolumn{2}{|c|}{ Group } & \multirow[b]{2}{*}{$\chi^{2}$} & \multirow[b]{2}{*}{$P$} \\
\hline & $\begin{array}{c}\text { Case (Diabetic) } \\
\text { No }(\%)\end{array}$ & $\begin{array}{l}\text { Control (Non- } \\
\text { diabetic) No }(\%)\end{array}$ & & \\
\hline $\begin{array}{c}\text { Normal vaginal } \\
\text { delivery }\end{array}$ & $32(40.5 \%)$ & $87(57.6 \%)$ & \multirow[t]{2}{*}{6.081} & \multirow[t]{2}{*}{0.010} \\
\hline Caesarean delivery & $47(59.5 \%)$ & $64(42.4 \%)$ & & \\
\hline Total & $79(100 \%)$ & $151(100 \%)$ & & \\
\hline
\end{tabular}

There was significant difference between diabetic and control groups regarding type of delivery either vaginal or caesarean deliveries as percentage of normal vaginal delivery among diabetic group was $40.5 \%$ while in control group was $57.6 \%$. Percentage of caesarean delivery among diabetic cases was $59.5 \%$ while in control was $42.4 \%$.

\section{DISCUSSION}

The demographic characteristics of diabetic and non-diabetic pregnant women are presented in table (1). Results show that the mean age, $(32.09 \pm 35$ years in diabetic group and $29.69 \pm 5.9$ years in control group) and there was significant difference between both groups $\mathrm{P}<0.001$. Regarding number of living children, abortions and stillbirth, there was significant difference between both groups. All these variables were higher among diabetic than non-diabetic women. These results are in agreement with study of (El-Maini et al., 2017) who reported that mean age, gravity and parity were significantly higher in diabetic group. The results are consistent also with (Egbe et al. 2018) who reported in their study that the risk factors identified in their work 32 
Journal of Environmental Sciences (JES)

Institute of Environmental Studies and Research, Ain Shams University

El-Sherbiny, Hanan et al.

among diabetic group were principally advanced maternal age ( $\geq 30$ years), obesity, past history of unexplained stillbirth and history of macrosomia. Yuliu et al. (2017) concluded in their study that, history of miscarriage and stillbirth is important predictor of GDM and can be used in screening the pregnant women who were at high risk of developing GDM and can help in reducing the incidence of GDM related morbidity and mortality in pregnant women. Regarding body mass index (BMI), there was no significant difference between both groups, and we found that almost all diabetic women in the study were overweight or obese. However, the mean of body mass index among control group was higher than diabetic group, and this may be due to the high prevalence of obesity among Egyptian women in general. AlEbshehy et al. (2016) reported that, in Egypt there is a remarkable increase in obesity with more than one third of the whole population being obese.

A particular issue in Egypt is that prevalence of obesity is more than double among females as compared to males and they concluded in their study that obesity among Egyptian females increases with urban residence, unhealthy diet and physical inactivity and their results revealed that the growing trend of obesity was among poor people and influenced by urbanization and level of education. As regard results of (27-28 weeks) scan, there was significant difference between diabetic and control groups regarding umbilical cord thickness and estimated fetal weight with $\mathrm{P}<0.001$ while there was no significant difference regarding abdominal circumference. Comparison between diabetic and control groups had been made at (36-37 weeks), Vol.(49); Iss.(1); No.(2); Jan.2020 
Journal of Environmental Sciences (JES)

Institute of Environmental Studies and Research, Ain Shams University

El-Sherbiny, Hanan et al.

regarding fetal sonographic parameters as a predictor for fetal macrosomia, there was significant-increase of abdominal circumference (AC) measurements among diabetic group $\mathrm{P}<0.001$ which is consistent with (Lee et al. 2014) who reported that fetal ACs measured during second and third trimesters are independent predictors of birth weight and macrosomia. Their study also demonstrated that fetal ACs are significant risk factors for macrosomia and also reported that significance of fetal AC measurements is maximized when it is measured in the third trimester. In the current study in addition to the traditional biometric estimation of fetal weight, umbilical cord thickness which was estimated by measuring Wharton's jelly (WJ) area was considered as an additional tool to predict birth weight by ultrasound. As regard umbilical cord thickness measurements at (36-37 weeks) there was significant difference between diabetic and control groups with $\mathrm{P}<0.001$ and when we compare between macrosomic and non-macrosomic fetuses at 36-37 weeks regarding umbilical cord thickness, there was significant difference with $\mathrm{P}<0.001$. These results are consistent with Binber et al. (2012) who found that umbilical cord area and Wharton's jelly area values were statistically larger at 36 weeks when macrosomic were compared with nonmacrosomic fetuses and they determined that Wharton's jelly area was the main factor for umbilical cord thickness related to fetal macrosomia. When comparison was done between diabetic and control groups regarding occurrence of fetal macrosomia it was $60 \%$ among diabetic group and $10 \%$ among control group and there was significant difference with $\mathrm{P}<0.001$. In 
Journal of Environmental Sciences (JES)

Institute of Environmental Studies and Research, Ain Shams University

El-Sherbiny, Hanan et al.

agreement with these results Nadir et al (2015) reported that the frequency of macrosomia in their study among diabetic women was $30.23 \%$ and macrosomic newborn were 5 times for mothers with diabetes compared to mothers without diabetes. Regarding frequency of low birth weight newborn in the current study was $4 \%$ among diabetic group, and all diabetic women of low birth weight newborn were diagnosed as pregestational diabetes mellitus. While the frequency of control group was $0.7 \%$ with $\mathrm{P}<0.001$ which demonstrates significant difference between the studied groups. This finding is in agreement with Gutaj and Ozegowsha (2016) who reported that maternal vasculopathy associated with long standing diabetes can be linked to placental dysfunction and subsequent fetal growth restriction. In the current study when comparison between macrosomic and non-macrosomic newborn regarding maternal HbA1c measured at (27-28 weeks) and (36-37 weeks) among diabetic women, there was significant difference between both groups with P 0.001 and 0.009 respectively. This result is consistent with Xin et al. (2018) who concluded in their study that women with HbAlc $\geq 6.5 \%$ during pregnancy have more than eight times the risk of having macrosomic infant as compared to women with $\mathrm{HbAlc}$ levels $<6.5 \%$ during pregnancy. Moreover, every $1 \%$ increase in HbA1c levels during pregnancy doubled the odds having macrosomic infant. In the present study, comparison between diabetic and control groups regarding fetal umbilical artery Doppler indices was done and there was significant difference between both groups regarding RI and S/D while no significant difference regarding PI. However, almost all 
Journal of Environmental Sciences (JES)

Institute of Environmental Studies and Research, Ain Shams University

El-Sherbiny, Hanan et al.

of cases were within normal range of Doppler indices except few cases of pregestational diabetes their Doppler indices were high in RI and S/D. These results are consistent with the study of Borna and Rahmani (2015) who concluded that pregnant diabetic females within controlled blood glucose and without any vasculopathy, pathological alterations in fetal and placental vessels wasn't enough to cause changes in blood flow and consequently alterations in Doppler ultrasound indices. In our study there was significant difference between diabetic and control groups, as abnormal environment of diabetic pregnancy, causing abnormal placental perfusion with alteration in blood flow of spinal artery and in Doppler ultrasound indices. Regarding occurrence of diabetic pregnancy complications rather than abnormal fetal growth in the present work, the frequency of preterm labour was $2.4 \%$ in diabetic group, they were 2 cases one from gestational diabetic women, and the other from pregestational diabetic women. Both cases were due to premature rupture of membranes (PROM). Regarding control group, there were 4 cases of preterm labour, 2 cases due to severe antepartum hemorrhage and 2 cases due to PROM. As regard percentage of intrauterine fetal death (IUFD) it was $2.4 \%$ among diabetic group. All from pregestational diabetic women. While among control group it was $0.6 \%$. This is in agreement with Boka and Nigatu (2019) as the incidence of intrauterine fetal demise in their study was 2.6\% (Rezai et al., 2016), reported that, diabetes is an independent risk factor for still birth that is amenable to achieving glycemic targets. Evidence based recommendations for antenatal screening glycemic management is warranted 
Journal of Environmental Sciences (JES)

Institute of Environmental Studies and Research, Ain Shams University

El-Sherbiny, Hanan et al.

to achieve reduction in still birth rates for gravidas with pregestational and gestational DM. In the current study percentage of pre-eclampsia was $4.9 \%$ among diabetic women with increased frequency among pregestational diabetics. While the percentage was 3.2\% among control group. In Jahan et al. (2016) study the incidence of pre-eclampsia among diabetic women was $17 \%$ while among non-diabetic was $13 \%$ and concluded that, there was an association had been found between the risk of developing pre-eclampsia and the presence of diabetes in pregnant patients of their study. These results are in agreement of the present work and the variations of the result may be due to awareness of prevention of diabetic related complications among mothers. As regarding mode of delivery in the present study it was normal vaginal delivery (NVD) in $40.5 \%$ of diabetic group with statistically significant increase among control group (57.6\%). Regarding frequency of diabetic women delivered by Cesarean section it was $59.5 \%$ while in control group it was $42.4 \%$. The higher rate of Cesarean section among diabetic group of the current study is explained by the higher rate of macrosomia and fetal birth weight of the same group. These results are consistent with results of Dudhwadkar and Fonseca (2016) who reported that percentage of diabetic patients delivered vaginally was $46 \%$. Whereas patients underwent Cesarean section were $52 \%$ and $2 \%$ by vacuum assisted delivery Boka and Negau (2019), reported that, $57.8 \%$ of diabetic women in their study delivered by Cesarean section and they reported that the higher rate of operative delivery was related to the higher incidence of macrosomia. 
Journal of Environmental Sciences (JES)

Institute of Environmental Studies and Research, Ain Shams University

El-Sherbiny, Hanan et al.

\section{CONCLUSION}

The results of the present study suggest the possibility of using sonographically determined fetal abdominal circumference, Whaton's jelly area, estimated fetal body weight measurements to distinguish women at high risk for abnormal fetal growth and disproportion, potentially resulting in early detection and reducing fetal morbidity. In addition, these parameters can be considered as an effective, noninvasive and cost-effective method that can prove useful for evaluating the fetal consequences of maternal hyperglycemia.

\section{REFERENCES}

Alebshehy R.; Shuaib N. M. and Mbako J. D. (2016): Determinant analysis of obesity among adult females in Egypt; The Egyptian Journal of Hospital Medicine; 65:662-669.

Al-Maini E. H.; Hamad L. H.; Yassir N. D. and Hamad S. H. (2017): Hemoglobin A1c and umbilical cord components: Prediction of fetal macrosomia in woman with Gestational Diabetes Mellitus. Eur Exp Biol; 7(2):1-4.

Binber B.; Yeniel A. O.; Ergenoglu A. M.; Kazandi F. and Sagol S. (2012): The role of umbilical cord thickness and HbA1c levels for the prediction of fetal macrosomia in patients with gestational diabetes mellitus. Arch Gynecol Obstet; 285:635-639.

Boka A. and Nigatu D. (2019): Assessment of adverse birth outcomes and associated factors among diabetic pregnant mothers who delivered at Mettu Karl Hospital, III Ubabor zone, South West Ethiopia-2018. Intern Med; 9(10):302-310. 
Borna S. and Rahmani Z. (2015): A study of Doppler ultrasound indices of spiral placental and umbilical arteries in pregnant women with singleton pregnancy suffering type-1 diabetes mellitus, gestational diabetes and normal pregnant women. J App Bio Sci; 5(105):436-440.

Daniela R. (2017): Fetal and neonatal complications of diabetic pregnancy. The Moldovan Medical Journal; 60(4):50-56.

Dudhwadkar A. R. and Fonseca M. N. (2016): Maternal and fetal outcome in gestational diabetes mellitus. Int J Reprod Contracept Gynecol; 5(10):3317-3321.

Egbe T. O.; Tsaku E. S.; Tchounzou R. and Ngowe M. N. (2018): Prevalence and risk factors of gestational diabetes mellitus in a population of pregnant women attending three health facilities in Lime, Cameroon: A Cross-Sectional Study. Pan Afr Med J; 31:195.

Gutaj P. and Ozegowsha E. W. (2016): Diagnosis and management of IUGR in pregnancy complicated by type 1 diabetes mellitus. Curr Diab Rep; 16:38-46.

Hegazi R. El-Gamal M.; Abdel-Hady N. and Hamdy O. (2015): Epidemiology of and risk factors for type 1 diabetes in Egypt. Annals of Global Health; 81(6):814-820.

Jahan M.; Mahbuba S.; Shaha S.; Akter H.; Ahsan G. U.; Islam T.; Kuehl T. J. and Uddin M. N. (2016): ID: 57: Pregestational diabetes and pre-eclampsia in Bangladeshi patients: A retrospective study. Journal of Investigative Medicine; 64(4) available from http://dx.doi.org/10.1136/Jim-2016-000120.99.

Langer O.; Yogev Y.; Most O. and Xenakis E. M. (2005): Gestational diabetes: the consequences of not treating. Am J Obstet Gynecol; 192:989-97. 
Lee B. H.; Park T. C. and Lee H. J. (2014): Association between fetal abdominal circumference and birth weight in maternal hyperglycemia. Acta Obstetrica et Gynecologica; 93:786-793.

Muhil M.; Sembian U.; Priyanka D. and Arun G. T. (2018): Correlation of ultrasonographic screening of umbilical cord parameters and adverse. Birth outcome in Gestational Diabetes Mellitus. Journal of Dental and Medical Sciences; (17):1-6.

Nadir S.; Jamil S. and Hamid M. (2015): The prevalence of macrosomia in newborns and its associated with maternal diabetes. J Med Sci; 23(1):3-6.

Reece E. A. and Homko C. J. (2007): Pre-pregnancy care and the prevention of fetal malformations in the pregnancy complicated by diabetes. Clin Obstet Gynecol; 50:990-997.

Rezai S.; Cokes C. W.; Gottimukkala S.; Penas R. P. and Chadee A. (2016): Review of stillbirths among antepartum women with gestational and pregestational diabetes. Obset Gynecol Int J; 4(4):00118.Dol:10.15406/ ogij. 2016.00118.

Williams W. K. (2011): Applications of Doppler studies for fetal surveillance in Diabetic Pregnancies, Gestational Diabetes; ISBN: 978-953307-581-5. Available from, http://www.inechopen.com/ books/gestational-diabetes/ applications-of-Doppler-studiesfor-fetal-surveillance in diabetic - pregnancies.

Xin S. C.; Pravin R. R.; Rajadurai V. S. and Chaudran S. (2018): Elevated glycated hemoglobin during pregnancy in diabetic women as a predictor of large-for gestational age infants in an Asia cohort. Journal of Clinical Neonatology; 7(3):136-140.

Yuliu L.; Zhang Y. and Li (2017): Risk factors of gestational diabetes among health Chinese women: an observational study. Biomedical Research; 28(5):2126-2130. 


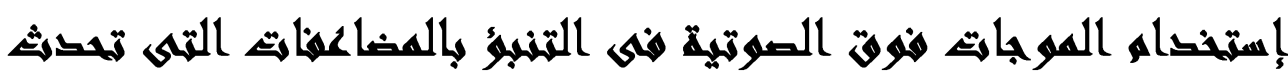

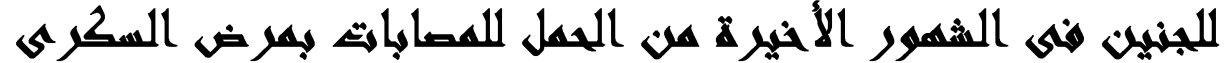

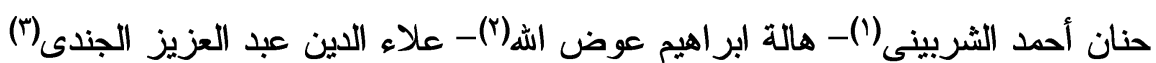

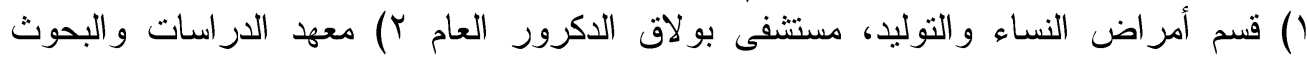

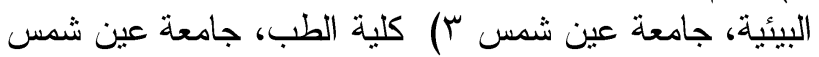

\section{المستخلص}

تعتبر حالات السكرى مع الحمل من الحالات الخطرة لأنه بصاحبها مضاعفات ومخاطر

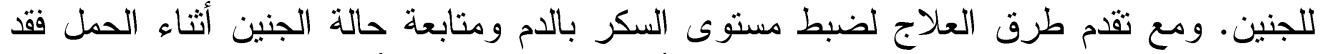

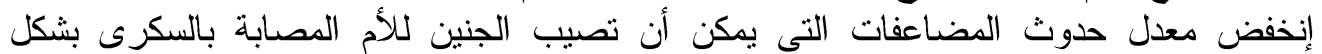

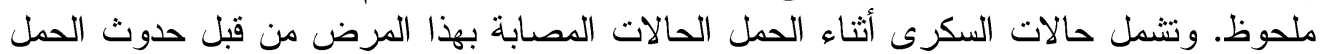

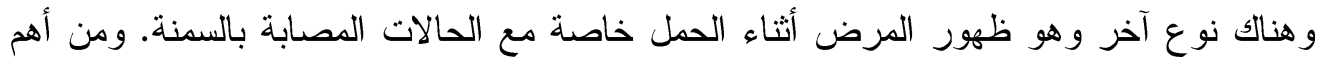

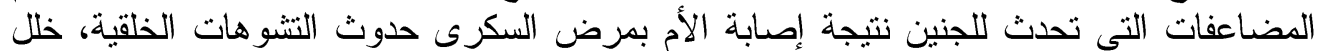

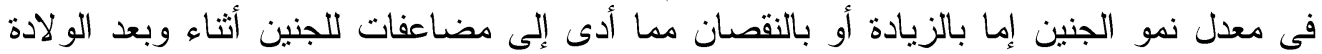

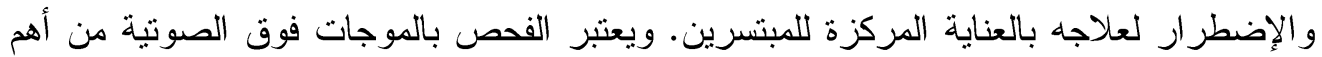

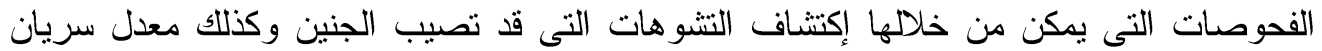

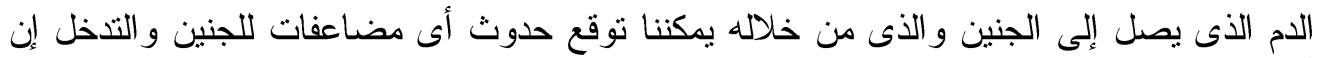

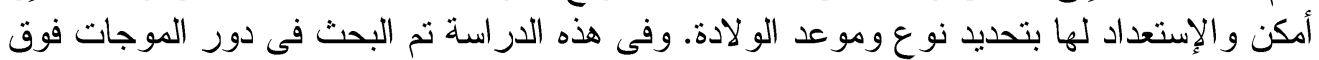
الصوتية فى التتبؤ بحدوث المضاعفات التى قد تحدث في شهور الحمل الحمل الأخبرة لأجنة الأمهات

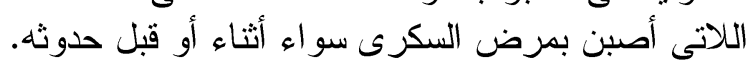

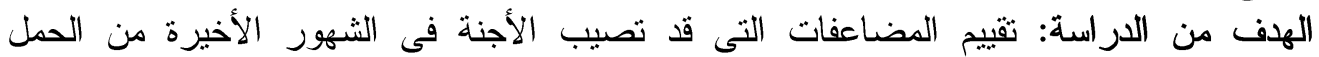

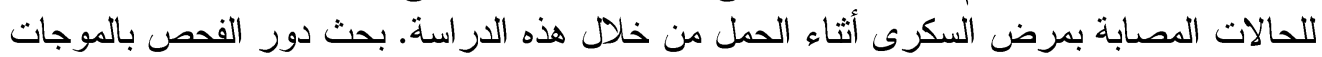

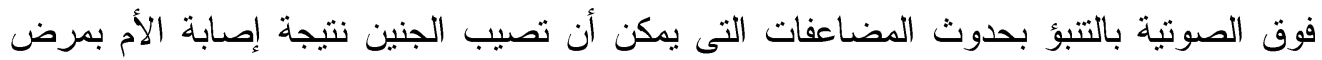

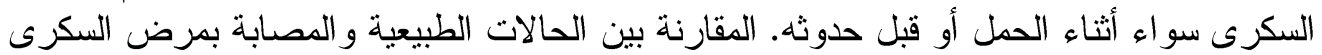

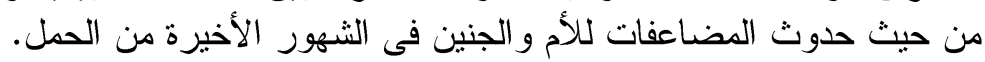

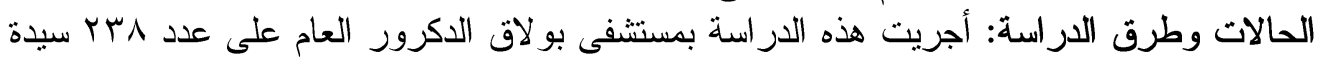

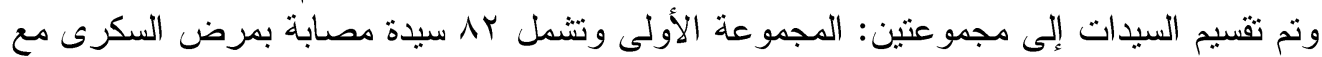

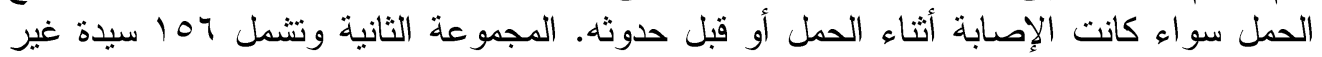

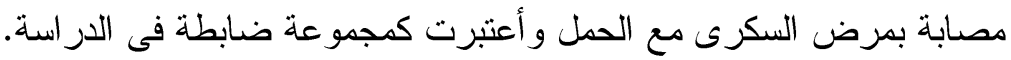
Vol.(49); Iss.(1); No.(2); Jan.2020 


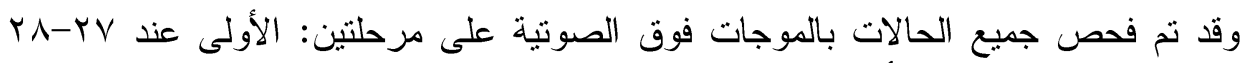

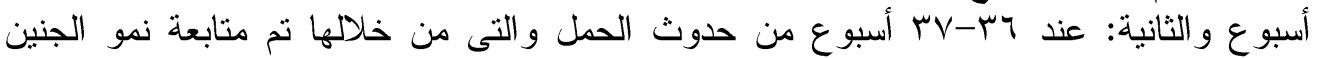
وذلك من خلال قياس وزن الجنين ومحيط البطن وكذللك سمك الحبل السرى. ومن خلانل جنال جهاز

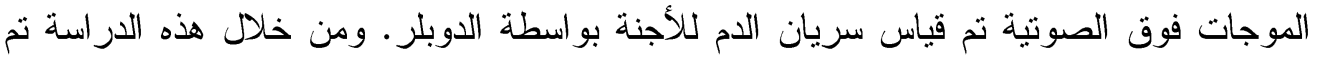

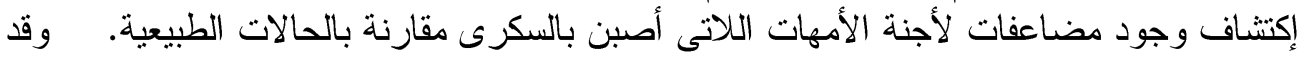

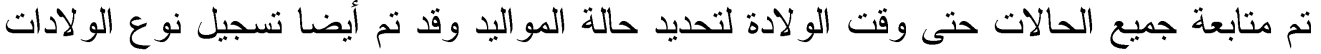

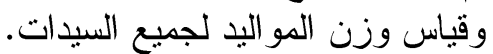

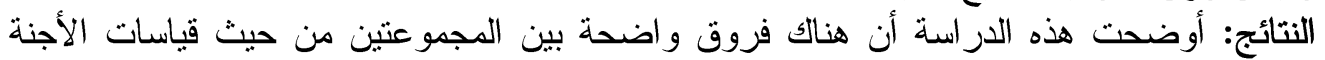

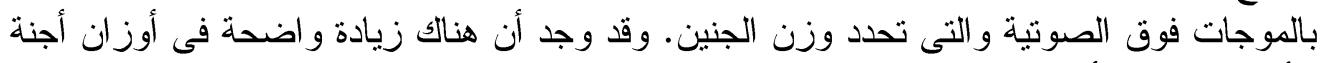

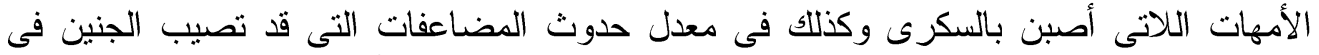

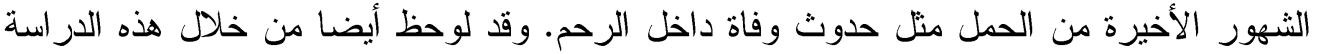

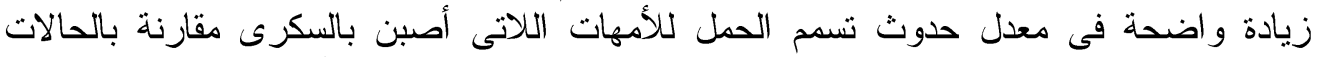

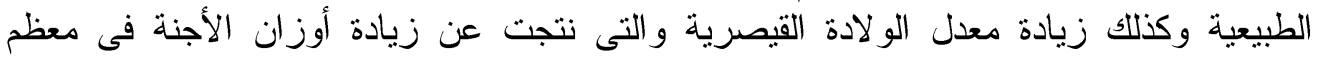

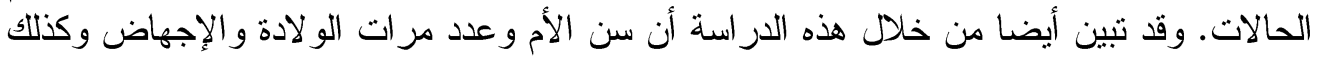

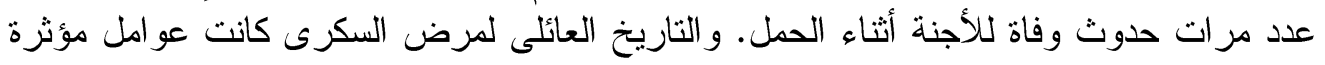
لحدوث مرض السكرى مع الحمل.

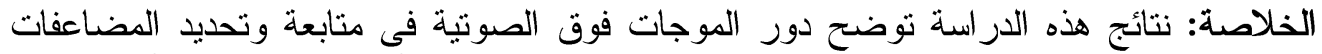

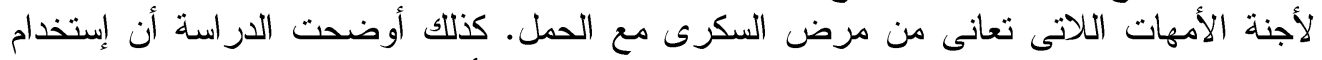

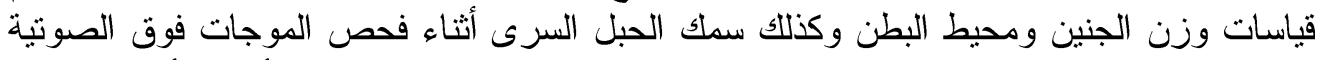

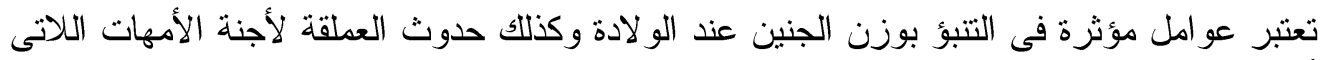

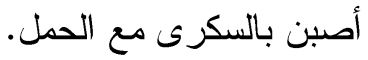

